\title{
Congenital Cytomegalovirus Infection and Maternal Varicella during Pregnancy. Is There a Coincidence? A Case Report
}

\author{
Claire Périllaud-Dubois ${ }^{1,2,3}$, Elise Bouthry ${ }^{1,2}$, François-Charles Javaugue ${ }^{1}$, Alexandra Letourneau ${ }^{2,4}$, \\ Aurore Bonnin ${ }^{2,4}$, Emmanuelle Letamendiaa ${ }^{2,5}$, Christelle Vauloup-Fellous ${ }^{1,2,6 *}$ \\ ${ }^{1}$ AP-HP, WHO Rubella National Reference Laboratory, Department of Virology, Paul-Brousse Hospital, Villejuif, France \\ ${ }^{2}$ Groupe de Recherche sur les Infections pendant la Grossesse (GRIG), Paris, France \\ ${ }^{3}$ IAME, INSERM UMR1137, University Paris Diderot, Paris, France \\ ${ }^{4}$ AP-HP, Service de Gynécologie-Obstétrique, Antoine Béclère Hospital, Clamart, France \\ ${ }^{5}$ AP-HP, Service de Néonatologie, Antoine Béclère Hospital, Clamart, France \\ ${ }^{6}$ INSERM U1193, University Paris Sud, Villejuif, France \\ Email: *christelle.vauloup@aphp.fr
}

How to cite this paper: Périllaud-Dubois, C., Bouthry, E., Javaugue, F.-C., Letourneau, A., Bonnin, A., Letamendia, E. and Vauloup-Fellous, C. (2019) Congenital Cytomegalovirus Infection and Maternal Varicella during Pregnancy. Is There a Coincidence? A Case Report. Open Journal of Obstetrics and Gynecology, 9, 1221-1225. https://doi.org/10.4236/ojog.2019.99119

Received: July 30, 2019

Accepted: September 3, 2019

Published: September 6, 2019

Copyright (c) 2019 by author(s) and Scientific Research Publishing Inc. This work is licensed under the Creative Commons Attribution International License (CC BY 4.0).

http://creativecommons.org/licenses/by/4.0/

\begin{abstract}
Background: Co-infections may represent substantial diagnostic and treatment challenges. Aim: To the better of our knowledge, we describe the first case in the literature of congenital Cytomegalovirus (CMV) infection following maternal CMV non primary infection contemporary to varicella during pregnancy. Case Presentation: A pregnant woman had a varicella during her pregnancy. Congenital CMV infection was fortuitously discovered in the neonate owing to a universal CMV screening. Retrospective analysis of maternal serums during pregnancy showed CMV reactivation. We aim to highlight that CMV reactivation could be due to varicella and discuss if it could facilitate the transplacental transmission of CMV. Conclusion: This case report emphasizes neonatal CMV screening, and warns against dual maternal infection especially because this may be at particular risk of transmission to the fetus.
\end{abstract}

Keywords

cCMV, VZV, Intercurrent Infection, Asymptomatic Congenital CMV Infection

\section{Introduction}

Congenital CMV (cCMV) infection can result from primary or non primary maternal CMV infection during pregnancy [1]. CMV reactivation can be in- 
duced by a variety of stimuli or conditions, including immunosuppressant administration, HIV infection and septic shock [2]. Therefore, maternal HIV infection is already described as a risk factor for cCMV [3] because of a higher risk of CMV reactivation. To the better of our knowledge, no case has been reported in the literature concerning CCMV infection following a maternal varicella during pregnancy.

\section{Case Report}

A 24-year-old primiparous pregnant woman, was referred to our hospital at 33 weeks of gestation (WG) because of a rash clinically identified as a varicella. Varicella primary-infection was laboratory-confirmed with a positive VZV (Varicella Zona Virus) PCR on blood and IgG VZV seroconversion (Figure 1). She received intravenous acyclovir $700 \mathrm{mg} 3$ times per day during 5 days and no complication was observed. Because of uterine contractions, tocolysis was introduced with atosiban (Tractocile ${ }^{\circledR}$ ). Despite the very low risk of fetopathy after $24 \mathrm{WG}$, regular ultrasound examinations were performed and were all normal. At $38 \mathrm{WG}$ the patient delivered an eutrophic baby girl after spontaneous labor.

In our maternity, universal screening for CMV congenital infection is performed at birth (research protocol) by CMV PCR on saliva swab in the delivery room. For this infant, screening CMV PCR was positive on saliva collected day one (6.63 log copies $/ \mathrm{mL}$ ), and confirmed positive on urine collected day three (6.19 log copies/mL) (Figure 1). Congenital CMV infection was therefore assessed for this neonate. She was asymptomatic at time of diagnosis and all complementary

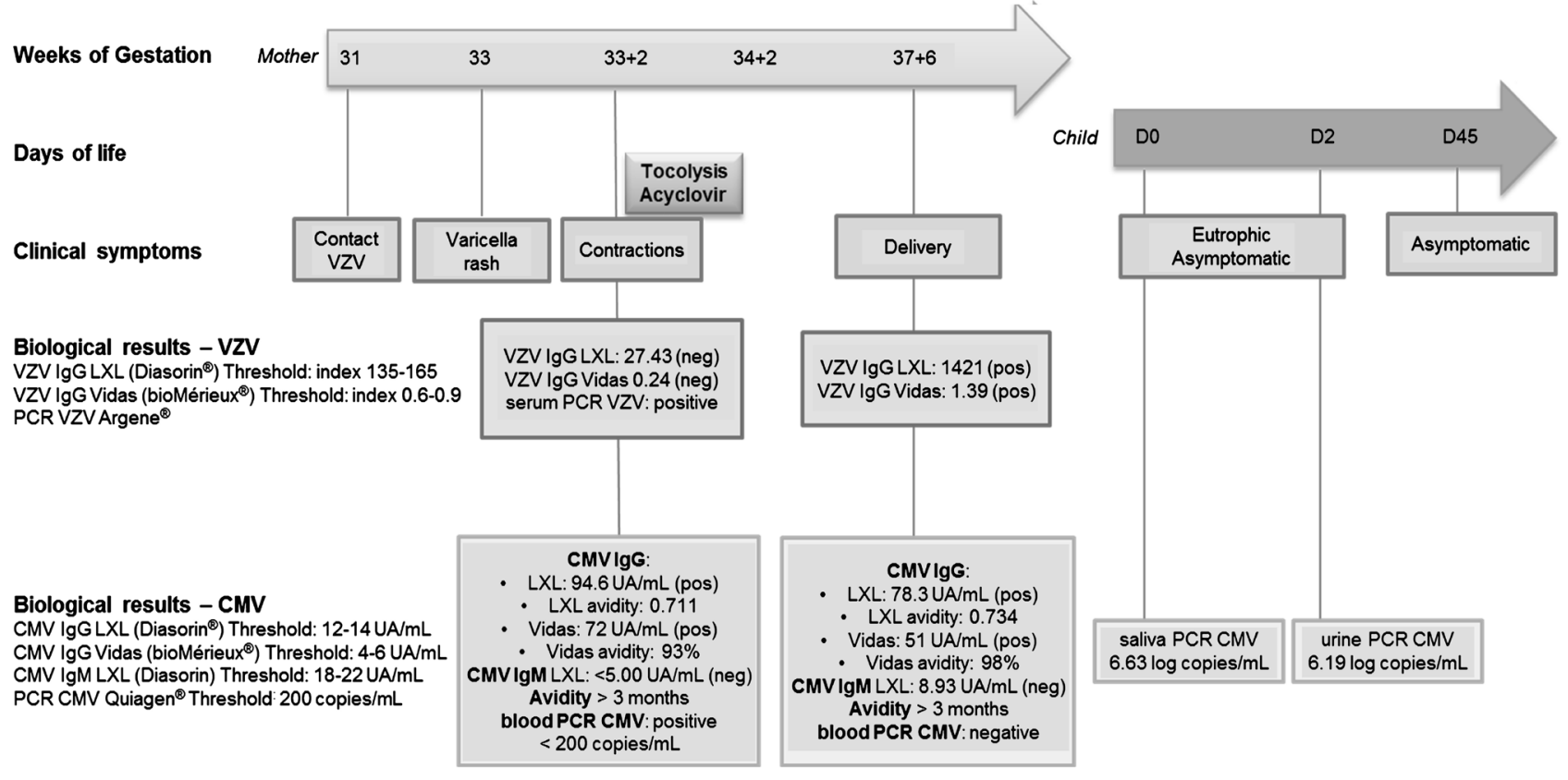

pos: positive; neg: negative

Figure 1. Chronology of the clinical story of the maternal varicella and the congenital CMV infection. The timeline repertories clinical symptoms and biological results obtained for VZV and CMV, both for the mother and the neonate according to gestational age and days of life respectively. 
examinations were normal: transfontanellar ultrasound, eye fundus examination, auditory brainstem response, blood count, liver function tests. Consequently, prognosis of this CMV congenital infection is excellent but a specific pediatric follow-up was set up because of the approximate $10 \%$ risk of delayed hearing impairment [1] [4] [5].

Retrospectively, we investigated maternal blood samples collected during pregnancy. The mother was seronegative for HIV. CMV IgM were always negative, and CMV IgG avidity was always high, which indicates that primary infection occurred before pregnancy. A low positive CMV PCR (29 copies $/ \mathrm{mL})$ on the blood sample collected at time of varicella rash was observed, indicating a CMV non primary infection (NPI) at that time (Figure 1). Finally, we hypothesized a probable CMV reactivation occurring during VZV primary infection, and subsequent transmission to the fetus born with asymptomatic congenital CMV infection.

\section{Discussion}

VZV and CMV are both Herpesviruses that can be acquired transplacentally. Incidence of congenital CMV infection is reported to be approximately $0.5 \%$ to $0.7 \%$ [6] in European countries, and is in France equally due to maternal CMV primary infection or NPI [7]. Both situations can cause fetal or neonatal complications. NPI are either reactivation of latent infection or re-infection with a different virus, but it is hardly possible to distinguish the two situations.

This case illustrates the risk of CMV non primary infection during another acute infection which is a well know phenomenon particularly for Herpesviruses. Indeed, these viruses establish latency after primary infection and can reactivate in different situations particularly when an intercurrent infection occurs [2] [8] [9] [10] [11]. As an example, Chêne et al. studied the effect of $P$. falciparum on reactivation of all human Herpesviruses and demonstrated that acute malaria was associated with reactivation of HSV-1 (Herpes Simplex Virus-1) and EBV (Epstein Barr Virus) [10]. Walton et al. showed that septic patients had higher viral loads of Herpesvirus in blood, in particular CMV [12]. Moreover, both Hioki et al. and Kasuya et al. described CMV reactivation concurrent with VZV infection in immunocompromised patients [13] [14]. This confirms that CMV reactivation during acute VZV infection is plausible, and we wonder if one could have facilitated transplacental transmission of the other. In support of this assumption, Van der Sande et al. studied the risk factors associated with CMV congenital infection in Gambia. They found active malaria infection to be a significant risk factor (adjusted OR 2.9, 95\%CI 1.0 - 8.4) and hypothesized that one established infection can facilitate the other to be transmitted congenitally [15]. They also observed that it was more common in primiparous women, as in the present case, suggesting that their immune response may differ from multiparous women.

In the present case, low CMV viremia without any serological argument for an 
acute infection, was in favor of CMV NPI. Consequently, the infant was born with CMV congenital infection, fortuitously discovered in the context of a systematic salivary screening at birth. To date, there is no international consensus to recommend universal screening for congenital CMV infection, but studies and discussions are ongoing. However, a targeted congenital CMV screening in case of maternal history of systemic infection could be discussed.

\section{Conclusion}

Although our case had asymptomatic congenital infection at birth, this case report emphasizes neonatal CMV screening, and warns against dual maternal infection especially because this may be at particular risk of transmission to the fetus.

\section{Conflicts of Interest}

The authors declare no conflicts of interest regarding the publication of this paper.

\section{References}

[1] de Vries, J.J.C., van Zwet, E.W., Dekker, F.W., Kroes, A.C.M., Verkerk, P.H. and Vossen, A.C.T.M. (2013) The Apparent Paradox of Maternal Seropositivity as a Risk Factor for Congenital Cytomegalovirus Infection: A Population-Based Prediction Model: Maternal Seropositivity as a Risk Factor for cCMV. Reviews in Medical Virology, 23, 241-249. https://doi.org/10.1002/rmv.1744

[2] Cook, C.H. and Trgovcich, J. (2011) Cytomegalovirus Reactivation in Critically Ill Immunocompetent Hosts: A Decade of Progress and Remaining Challenges. Antiviral Research, 90, 151-159. https://doi.org/10.1016/j.antiviral.2011.03.179

[3] Adachi, K., Xu, J., Ank, B., Watts, D.H., Camarca, M., Mofenson, L.M., et al. (2018) Congenital Cytomegalovirus and HIV Perinatal Transmission. The Pediatric Infectious Disease Journal, 37, 1016-1021. https://doi.org/10.1097/INF.0000000000001975

[4] Hadar, E., Dorfman, E., Bardin, R., Gabbay-Benziv, R., Amir, J. and Pardo, J. (2017) Symptomatic Congenital Cytomegalovirus Disease Following Non-Primary Maternal Infection: A Retrospective Cohort Study. BMC Infectious Diseases, 17, Article No. 31. https://doi.org/10.1186/s12879-016-2161-3 http://bmcinfectdis.biomedcentral.com/articles/10.1186/s12879-016-2161-3

[5] Giannattasio, A., Di Costanzo, P., De Matteis, A., Milite, P., De Martino, D., Bucci, L., et al. (2017) Outcomes of Congenital Cytomegalovirus Disease Following Maternal Primary and Non-Primary Infection. Journal of Clinical Virology, 96, 32-36. https://doi.org/10.1016/j.jcv.2017.09.006

[6] Foulon, I., Naessens, A., Foulon, W., Casteels, A. and Gordts, F. (2008) A 10-Year Prospective Study of Sensorineural Hearing Loss in Children with Congenital Cytomegalovirus Infection. The Journal of Pediatrics, 153, 84-88.

https://doi.org/10.1016/j.jpeds.2007.12.049

[7] Leruez-Ville, M., Magny, J.-F., Couderc, S., Pichon, C., Parodi, M., Bussières, L., et al. (2017) Risk Factors for Congenital Cytomegalovirus Infection Following Primary and Nonprimary Maternal Infection: A Prospective Neonatal Screening Study Using Polymerase Chain Reaction in Saliva. Clinical Infectious Diseases, 65, 398-404. 
https://doi.org/10.1093/cid/cix337

[8] Regunath, H., Shivashankara, K.N., Sundeep, K.B. and Bhaskar, A.P. (2008) Reactivation of Herpes Zoster in an Adult with Plasmodium Infection. Journal of Vector Borne Diseases, 45, 251-253.

[9] Ericsdotter, A.-C., Brink, M., Studahl, M. and Bengnér, M. (2015) Reactivation of Herpes Simplex Type 1 in Pneumococcal Meningitis. Journal of Clinical Virology, 66, 100-102. https://doi.org/10.1016/j.jcv.2015.03.014

[10] Chêne, A., Nylén, S., Donati, D., Bejarano, M.T., Kironde, F., Wahlgren, M., et al. (2011) Effect of Acute Plasmodium falciparum Malaria on Reactivation and Shedding of the Eight Human Herpes Viruses. PLoS ONE, 6, e26266. https://doi.org/10.1371/journal.pone.0026266

[11] Nakamura, T., Daikoku, T., Shiraki, K. and Hayashi, A. (2015) Detection of Cytomegalovirus in an Immunocompetent Adult Presenting with Acute Retinal Necrosis Due to Varicella-Zoster Virus: A Case Report. Clinical Ophthalmology, 9, 853-858. https://doi.org/10.2147/OPTH.S81020

[12] Walton, A.H., Muenzer, J.T., Rasche, D., Boomer, J.S., Sato, B., Brownstein, B.H., et al. (2014) Reactivation of Multiple Viruses in Patients with Sepsis. PLoS ONE, 9, e98819. https://doi.org/10.1371/journal.pone.0098819

[13] Hioki, T., Takama, H., Makita, S., Watanabe, K., Watanabe, D. and Akiyama, M. (2018) Cytomegalovirus Reactivation Accompanied by Varicella Zoster Virus Reactivation or Reinfection in an Adult Patient of Multiple Myeloma during Bortezomib Therapy. The Journal of Dermatology, 45, 108-109. https://doi.org/10.1111/1346-8138.13744

[14] Kasuya, A., Kaneko, Y., Enomoto, N., Suda, T. and Tokura, Y. (2015) Simultaneous Reactivation of Cytomegalovirus in an Adult Patient with Varicella. The Journal of Dermatology, 42, 658-659. https://doi.org/10.1111/1346-8138.12858

[15] van der Sande, M.A.B., Kaye, S., Miles, D.J.C., Waight, P., Jeffries, D.J., Ojuola, O.O., et al. (2007) Risk Factors for and Clinical Outcome of Congenital Cytomegalovirus Infection in a Peri-Urban West-African Birth Cohort. PLOS ONE, 2, e492. https://doi.org/10.1371/journal.pone.0000492

\section{List of Abbreviations}

CMV: Cytomegalovirus

cCMV: Congenital Cytomegalovirus

WG: Weeks of Gestation

VZV: Varicella Zona Virus

NPI: Non Primary Infection

HSV-1: Herpes Simplex Virus 1

EBV: Epstein Barr Virus 